\title{
Predisposing, enabling and need factors associated with skilled delivery care utilization among reproductive-aged women in Kersa district, eastern Ethiopia
}

\author{
Gezahegn Tesfaye ${ }^{1,2^{*}}$, Catherine Chojenta ${ }^{2}$, Roger Smith ${ }^{3}$ and Deborah Loxton ${ }^{2}$
}

\begin{abstract}
Background: Skilled delivery care utilization in Ethiopia is still very low compared with the goal set by the global community for countries with the highest maternal mortality. As a result, the country is overburdened with high maternal morbidity and mortality. We aimed to explore the predisposing, enabling, and need factors associated with skilled delivery care utilization among reproductive-aged women in Kersa district, eastern Ethiopia.

Methods: A community-based cross-sectional study was conducted with a total of 1294 women. The participants were selected using systematic sampling techniques. An interviewer-administered structured questionnaire aided by an electronic survey tool was used to collect data. Univariate analyses were conducted to describe the study sample. Bivariate and multivariate logistic regression analyses were carried out to elicit the association of predisposing, enabling, and need factors associated with skilled delivery care utilization. Separate multivariate models were fitted for primiparous and multiparous women categories. Odds ratios with $95 \%$ confidence intervals were used to assess statistical significance.

Results: More than a quarter (30.8\%) of the women surveyed used skilled delivery care for their most recent birth. Significant predisposing factors were as follows: presence of educated family member; receiving education on maternal health; previous use of skilled delivery care; and best friend's use of maternal care. Place of residence was the enabling factor that predicted skilled delivery care use. Antenatal care attendance and pregnancy intention were significant need factors associated with skilled delivery care utilization.

Conclusion: The findings of the study highlight the need for a concerted effort to establish community-based peer education programs; improve access to family planning services (to reduce unintended pregnancies); increase antenatal care uptake; and facilitate access to skilled delivery care in rural areas.
\end{abstract}

Keywords: Skilled delivery care, Predisposing factors, Enabling factors, Need factors, Reproductive-aged women, Kersa district, Eastern Ethiopia

\footnotetext{
*Correspondence: gezites@gmail.com

${ }^{1}$ School of Public Health, College of Health and Medical Sciences, Haramaya

University, P.O Box: 235, Harar, Ethiopia

${ }^{2}$ Research Centre for Generational Health and Ageing, Faculty of Health and

Medicine University of Newcastle, Newcastle upon Tyne, NSW, Australia

Full list of author information is available at the end of the article
}

(c) The Author(s). 2019 Open Access This article is distributed under the terms of the Creative Commons Attribution 4.0 International License (http://creativecommons.org/licenses/by/4.0/), which permits unrestricted use, distribution, and reproduction in any medium, provided you give appropriate credit to the original author(s) and the source, provide a link to the Creative Commons license, and indicate if changes were made. The Creative Commons Public Domain Dedication waiver (http://creativecommons.org/publicdomain/zero/1.0/) applies to the data made available in this article, unless otherwise stated. 


\section{Plain English summary}

Giving birth with the assistance of skilled health care professionals is referred to as skilled delivery care. Skilled delivery care is important to prevent maternal deaths that result from birth-related complications. Increasing the use of skilled delivery care is advocated as an important strategy to reduce maternal mortality. However, many women in developing countries such as Ethiopia do not wish to give birth at health facilities attended with skilled health care professionals. In Ethiopia, nearly three-quarters of women give birth at home, and the rate of skilled delivery care utilization is very low. The purpose of this study was to identify the key factors that are associated with skilled delivery care utilization in a largely rural district in Eastern Ethiopia. We conducted a community based crosssectional study which involved a face to face interview with eligible women. A total of 1294 eligible women completed the interview. Data were summarized descriptively, and the key factors associated with the use of skilled delivery care were identified using regression analysis. The results indicated that more than a quarter of the women attended skilled delivery care for their last birth. Having an educated family member, receiving maternal health education, previous use of skilled delivery care, having a best friend who used maternal care, urban residence, intended pregnancy, and antenatal care use during their last pregnancy were facilitating factors for skilled delivery care utilization. These findings highlight the need to institute measures that include these factors to improve the use of skilled delivery care.

\section{Introduction}

Globally, an estimated 303,000 women died due to pregnancy and childbirth complications in 2015, with developing countries accounting for nearly $99 \%$ of the global burden [1]. Although most maternal deaths that result from pregnancy complications are avoidable; all pregnancies that continued to birth could face obstetric complications that might not be identified during antenatal care (ANC) check-ups. Hence, the presence of a skilled health worker at birth for every delivery remains a crucial factor for the improvement of obstetric outcomes [2] and prevention of maternal deaths that occur during delivery [3]. Up to one-third of maternal mortality could be prevented by the appropriate management of birth complications by skilled health workers during birth [4].

A review of studies in Ethiopia [5] identified very low utilization of professionally assisted delivery care at a health facility as one of the main contributing factors to the existing high burden of maternal deaths in the country. Hence, promoting skilled delivery care attendance at health facilities is an essential strategy to prevent maternal mortality $[6,7]$.
Skilled delivery care attendance is low in most developing countries, with some of the lowest rates of attendance in sub-Saharan African countries [8], where the majority of maternal deaths occur [9]. In Ethiopia, according to a recent Demographic and Health Survey report, the proportion of women who utilized skilled birth assistance during delivery was $28 \%$ [10]. However, the global community has set a goal of reaching $60 \%$ utilization of skilled delivery care attendance during birth for countries with the highest maternal mortality, and $90 \%$ at a global level [11]. Based on the trend of data in the two decades before 2010, the estimated rate of annual improvement in the utilization of skilled delivery care in Ethiopia between the years 2011 to 2015 is $0.4 \%$, which is also far lower than the average rate of improvement in other sub-Saharan African countries [12]. Many other studies [13-18] on skilled delivery care utilization in Ethiopia found less than $40 \%$ of pregnant women accessed these services.

A multitude of factors including place of residence, education, wealth status, pregnancy intention, parity, birth order, previous use of care, physical distance, and cultural barriers are associated with skilled delivery care utilization [19-26]. However, there is limited evidence as to the contextual personal, social, and community factors that motivate a majority of pregnant women in Ethiopia to avoid delivering their babies with the assistance of skilled health workers. The existing evidence is restricted to identifying the comprehensive factors influencing skilled delivery care utilization and does not reflect the underlying regional variations in socioeconomic, geographic, and cultural influences. Consequently, there is a need to understand the regional level contextual factors operating as barriers in the utilization of skilled delivery care, to better inform context-specific interventions. In this study, we attempt to understand the factors associated with skilled delivery care attendance by using the Andersen and Newman behavioural model of health care utilization [27, 28]. This model typically classifies the factors that influence utilization of health care into three categories. The predisposing factors are the demographic and social conditions that influence the person's decision to use the service. The enabling factors are economic circumstances that facilitate service utilization. The need factors reflect the perceived health service needs and are related to the actual illness condition. The aim of this study was to assess the influence of these three factors on skilled delivery care utilization among reproductive-aged women in Kersa district, eastern Ethiopia.

\section{Methods}

\section{Study area and period}

The study was conducted in Kersa district, East Hararghe zone, Oromia region, eastern Ethiopia. Kersa town, the 
capital of the district, is located $486 \mathrm{kms}$ from Addis Ababa, the capital city of Ethiopia. The total population of the district was 205,628, as of the 2014 population projection for Ethiopia. In the district, there were 38 kebeles (the lowest administrative unit in Ethiopia consisting of 5000 people or 1000 households) or so-called subdistricts. From the 38 kebeles, three were urban, and 35 were rural $[29,30]$, and 24 kebeles were under the Health and Demographic Surveillance System (HDSS). There were seven health centres, 34 health posts and eight private pharmacies in the district. The health centres routinely provide the recommended packages of ANC, skilled delivery care and postnatal care. Based on a recent report from the district health office, the health coverage of the district was $80 \%$ [31]. The study was conducted from June to August 2017.

\section{Study design}

A community-based cross-sectional study was implemented.

\section{Population}

The population for the study were all reproductive-aged women living in the Kersa district. Only women who had at least one birth within the previous 3 years, had lived in the district for more than 6 months, and had delivered their most recent baby after 28 weeks of gestation were included. Women who were critically ill, and physically or mentally disabled were excluded from the study.

\section{Sample size and sampling procedure}

The total sample size for the study $(n=1320)$ was primarily calculated for a study on maternal health service utilization and associated factors in Kersa district, eastern Ethiopia using different parameters. Twenty-five percent of the total 38 kebeles in the district (i.e. 10 kebeles) were included in the study to ensure optimum sample representation. Of the included kebeles, two were urban, and eight were rural. The study district was first stratified into urban and rural kebeles, and these were further classified into HDSS and non-HDSS kebeles. A proportional number of study kebeles were then selected from each stratum using simple random sampling technique. To select the individual study participants, first, the number of households having at least one eligible woman was determined in each kebele using the Health Extension Workers' logbook. Since the number of households with eligible women varied among the included kebeles, the total sample size of the study was proportionally allocated to each selected kebele. The total calculated sample size was then proportionally allocated to each kebele based on the determined number of households with eligible women for each kebele. The study participants were drawn from the list of households having eligible women using systematic random sampling techniques. The participants were recruited at the time of the survey based on a preidentified list of randomly selected households. In the event of two or more eligible women being in the same household, only one woman was randomly selected and interviewed to avoid intra-household correlations.

\section{Measurement variables \\ Outcome variable}

Skilled delivery care utilization: women who have received delivery care from a skilled health worker (doctors, midwives/nurses, or health officers) at the time of labour and parturition of their most recent baby irrespective of the setting in which the birth occurs.

\section{Covariates}

(i) Predisposing factors: Woman's age; educational status; partner's educational level; presence of another educated family member; age at marriage; birth order; age at first pregnancy; education about maternal health; previous use of skilled delivery care; living in model family; best friend's use of maternal care; plus mass media and telephone availability at the household level.

(ii) Enabling factors: Residence; wealth index; decision making on household expenses; proximity to the nearest health facility; social support; and, gender of the household head.

(iii) Need factors: Health Extension Workers household visits; experience of still-birth; ever had an abortion; pregnancy intention; ANC attendance for the index pregnancy; history of infant death; and, experience of delivery complications.

\section{Source of data and data collection methods}

A supervisor and eight enumerators were involved in the data collection process. The data were collected using a structured questionnaire administered by face to face interviews at the participant's home. The survey questionnaire was adapted from relevant literature [32-36] that addresses maternal health service utilization. Variables were measured using closed ended questions and participants were queried about basic sociodemographic variables; reproductive histories; primary health care services; health promotion and women's autonomy; pregnancy status and maternal health service utilization; social network; and, social support. Using the translation-back-translation method, first, the original English version of the questionnaire was translated to the local language, Oromiffa. The Oromiffa version was then translated back into English by a translator who was not involved in the first phase of the translation 
process. The interviews were conducted using the local language. An off-line mode of digital data collection software (Survey Gizmo) installed on iPads was used to collect the responses. Kersa HDSS resident enumerators fluent in the local language conducted the individual interviews. A field supervisor and the lead author closely monitored the data collection at the field level.

\section{Data quality control}

Pre-testing of the tool was carried out on $5 \%$ of the sample of women in the adjacent district. Necessary refinements were made on the tool based on the pre-test findings. We recruited and employed experienced local data collectors and a supervisor. Intensive training was provided to the data collectors and the supervisor on the objectives of the study, methodology, and sampling procedures and how to use the iPads for collecting responses. The use of iPads during data collection prevented the potential for incomplete responses and missing values. At the field level, $10 \%$ of the interviewed women were re-interviewed by the supervisor to check the validity of the responses. During the quality check, if the supervisor found any invalid response on the Survey Gizmo, the interviewer revisited the house and interviewed the woman again. The enumerators uploaded the responses daily to the online version of Survey Gizmo. The responses were then double-checked daily by the lead author for any inconsistencies.

\section{Data management and analysis}

Data were analyzed using SPSS version 23 software package. We conducted the transformation of some of the variables to allow for undertaking a meaningful analysis. For the transformation, we used either recoding (through collapsing categories of some nominal variables and categorizing continuous variables) or creating new variables from the existing ones using statistical computation techniques. Univariate analyses were conducted to descriptively summarize the characteristics of the sample population. The existence of multicollinearity between covariates was determined using a Variance Inflation Factor value less than five. The multivariate model fitness was verified using Hosmer-Lemeshow test. Bivariate logistic regression analysis was carried out to compare utilization of skilled delivery care among different groups using $p$-value. Variables that showed statistical association at a p-value less than 0.05 from each set of variables in the bivariate analysis were entered into the final full multivariate logistic regression model. Two multivariate logistic regression models were fitted (Model 1 for multiparous women and Model 2 for primiparas women) to identify factors associated with skilled delivery care utilization. The measure of association using Adjusted Odds Ratios (AOR) with Confidence Intervals
(CI) was used to assess the direction as well as the strength of the association between the explanatory and the outcome variables.

\section{Ethical considerations}

The study was conducted after securing ethical approval from the Human Research Ethics Committee of the University of Newcastle, Australia and the Institutional Health Research Ethics Review Committee of College of Health and Medical Sciences, Haramaya University, Ethiopia. Informed verbal consent was obtained from each respondent before commencing the interviews. The confidentiality of the respondents was ensured by avoiding personal identification details. During houseto-house interviews, the participants' privacy was maintained by carrying out the interviews in a separate place in their residence where auditory and visual privacy was assured.

\section{Result}

\section{Socio-demographic characteristics}

In this study, of the 1320 women who were approached, a total of 1294 women gave complete responses for the interviews. Out of these, $50.4 \%$ were aged $25-34$ years with a mean age of $27.4( \pm 6)$ years. The dominant ethnicity and religion were Oromo (98.5\%) and Muslim (96.8\%) respectively. Married women were nearly $98.7 \%$ of the sample, and about one quarter had at least an elementary school education (Table 1).

\section{Reproductive characteristics of the women}

More than three-fourths (83.3\%) of the women had been pregnant more than once, and 1059 (81.8\%) of the women had given birth more than once. Small numbers of respondents, 95 (7.4\%), 94 (7.3\%), and 264 (20.4\%) had ever experienced still-birth, abortion and infant death respectively. More than a quarter of the women (29.1\%) admitted that their most recent pregnancy was unintended. About 1114 (86.1\%) of the women were first married when they were less than 18 years of age, and 1155 (89.3\%) of the women became pregnant for the first time at the age of 20 years or less. For 671 (51.9\%) of the women, their most recent child was their third or less pregnancy, and for 1275 (98.5\%) of the women, their most recent child was a full-term delivery. More than half ( 693 or $53.6 \%$ ) of the women had attended at least one ANC for their most recent pregnancy (Table 2).

\section{Skilled delivery care utilization}

The utilization of skilled delivery care for the pregnancy or pregnancies prior to the most recent was $20.1 \%$. The proportion of women who attended skilled delivery care for the most recent birth was $30.8 \%$ regardless of the place of birth, whilst 384 (29.7\%) of the births were 
Table 1 Distribution of socio-demographic characteristics by place of residence among women in Kersa district, eastern Ethiopia, 2017

\begin{tabular}{|c|c|c|c|}
\hline \multirow[t]{2}{*}{ Variables } & Rural & Urban & Total \\
\hline & $N(\%)$ & $N(\%)$ & $N(\%)$ \\
\hline \multicolumn{4}{|l|}{ Age $(n=1294)$} \\
\hline $15-24$ & $353(31.5)$ & $58(33.1)$ & $411(31.8)$ \\
\hline $25-34$ & $558(49.9)$ & $94(53.7)$ & $652(50.4)$ \\
\hline $35-49$ & $208(18.6)$ & $23(13.1)$ & $231(17.9)$ \\
\hline \multicolumn{4}{|l|}{ Marital status $(n=1294)$} \\
\hline Married & $1105(98.7)$ & $172(98.3)$ & $1277(98.7)$ \\
\hline Divorced & $4(0.4)$ & $1(0.6)$ & $5(0.4)$ \\
\hline Never married & $1(0.1)$ & $2(1.1)$ & $3(0.2)$ \\
\hline Separated & $2(0.2)$ & $0(0.0)$ & $2(0.2)$ \\
\hline Widowed & $7(0.6)$ & $0(0.0)$ & $7(0.5)$ \\
\hline \multicolumn{4}{|l|}{ Wealth index $(n=1294)$} \\
\hline Highest & $208(18.6)$ & $50(28.6)$ & $258(19.9)$ \\
\hline Fourth & $204(18.2)$ & $57(32.6)$ & $261(20.2)$ \\
\hline Middle & $228(20.4)$ & $32(18.3)$ & $260(20.1)$ \\
\hline Second & $243(21.7)$ & $15(8.6)$ & $258(19.9)$ \\
\hline Lowest & $236(21.1)$ & $21(12.0)$ & $257(19.9)$ \\
\hline \multicolumn{4}{|l|}{ Ethnicity $(n=1294)$} \\
\hline Oromo & $1118(99.9)$ & $156(89.1)$ & $1274(98.5)$ \\
\hline Amhara and Arab & $1(0.1)$ & 19 (10.9) & $20(1.5)$ \\
\hline \multicolumn{4}{|l|}{ Religion $(n=1294)$} \\
\hline Muslim & 1115 (99.6) & $138(78.9)$ & $1253(96.8)$ \\
\hline Protestant and Orthodox & $4(0.4)$ & $37(21.1)$ & $41(3.2)$ \\
\hline \multicolumn{4}{|l|}{ Occupational status $(n=1294)$} \\
\hline Housewife & $1099(98.2)$ & $141(80.6)$ & $1240(95.8)$ \\
\hline Government employee & $1(0.1)$ & $23(13.1)$ & $24(1.9)$ \\
\hline Merchant & $8(0.7)$ & $11(6.3)$ & $19(1.5)$ \\
\hline Farmer & $11(1.0)$ & $0(0.0)$ & $11(0.9)$ \\
\hline \multicolumn{4}{|l|}{ Educational status $(n=1294)$} \\
\hline Never attended & $889(79.4)$ & $52(29.7)$ & $941(72.7)$ \\
\hline Elementary & $205(18.3)$ & $62(35.4)$ & $267(20.6)$ \\
\hline Secondary & $23(2.1)$ & $38(21.7)$ & $61(4.7)$ \\
\hline Tertiary & $2(0.2)$ & $23(13.1)$ & $25(1.9)$ \\
\hline \multicolumn{4}{|l|}{ Partner's education $(n=1279)$} \\
\hline Never attended & $620(55.4)$ & $25(14.3)$ & $645(49.8)$ \\
\hline Elementary & $394(35.2)$ & $44(25.1)$ & $438(33.8)$ \\
\hline Secondary & $88(7.9)$ & $45(25.7)$ & $133(10.3)$ \\
\hline Tertiary & $5(0.4)$ & $58(33.1)$ & $63(4.9)$ \\
\hline \multicolumn{4}{|c|}{ Partner's occupation ( $n=1279)$} \\
\hline Farmer & $1090(97.4)$ & $66(37.7)$ & $1156(89.3)$ \\
\hline Government employee & $6(0.5)$ & $59(33.7)$ & $65(5.0)$ \\
\hline Merchant & $7(0.6)$ & $22(12.6)$ & $29(2.2)$ \\
\hline Daily labourer & $4(0.4)$ & $25(14.3)$ & $29(2.2)$ \\
\hline
\end{tabular}

Table 1 Distribution of socio-demographic characteristics by place of residence among women in Kersa district, eastern Ethiopia, 2017 (Continued)

\begin{tabular}{llll}
\hline Variables & $\begin{array}{l}\text { Rural } \\
N(\%)\end{array}$ & $\begin{array}{l}\text { Urban } \\
N(\%)\end{array}$ & $\begin{array}{l}\text { Total } \\
N(\%)\end{array}$ \\
\hline Educated family member $(n=1294)$ & & \\
$\quad$ Never attended & $672(60.1)$ & $48(27.4)$ & $720(55.6)$ \\
Elementary & $366(32.7)$ & $70(40.0)$ & $436(33.7)$ \\
Secondary & $75(6.7)$ & $35(20.0)$ & $110(8.5)$ \\
Tertiary & $6(0.5)$ & $22(12.6)$ & $28(2.2)$ \\
\hline
\end{tabular}

assisted by a skilled health provider at a health facility. Slightly under half (194 or 48.9\%) of the women opted for health facility delivery because it was close to where they lived; whilst almost a quarter (91 or 22.9\%) cited high-quality services as a motivating factor. Among the women who delivered at the health facility, the final decision to deliver there was made by the respondent themselves (49.1\%), followed by their husbands (21.7\%). About 235 (59.2\%) of the women did not make any arrangement or birth plan prior to delivering the most recent child. A high proportion (305 or $76.8 \%$ ) of the women, were accompanied to a health facility for delivery by their partner, followed by traditional birth attendants (53 or 13.4\%) and Women's Development Army leaders (50 or 12.6\%) (Table 3).

\section{Referral, prior plan for facility birth and delivery complications}

Among the women who presented for delivery at the health facility, $46(11.6 \%)$ were referred to a higher-level health facility for delivery. More than three-quarters (317 or 79.8\%) of the women had a prior plan for facility delivery for their most recent birth. Only 94 (7.3\%) of the women experienced obstetric complications during the delivery of their most recent baby, with prolonged labour (36.2\%) and severe bleeding (29.8\%) being the most common types of complications. Out of those women who delivered their most recent baby at a health facility, 90 (22.7\%) did not recommend facility delivery to their friends. A significant proportion of women (364 or $28.1 \%$ ) still wished to deliver their next baby at home (Table 4).

\section{Factors associated with skilled delivery care utilization Predisposing factors}

Multiparous women who had educated family members had an increased odds of skilled delivery care attendance (AOR, 1.89; 95\% CI: 1.26, 2.85) than women who had no educated family members. Primipara women who had received education on maternal health had higher odds of using skilled delivery care (AOR, 2.22; 95\% CI: 1.09, 
Table 2 Reproductive characteristics of the women, Kersa district, eastern Ethiopia

\begin{tabular}{|c|c|c|}
\hline Variables $(n=1294)$ & Frequency & Percentage \\
\hline \multicolumn{3}{|l|}{ Age of marriage } \\
\hline$<18$ years & 1114 & 86.1 \\
\hline$\geq 18$ years & 180 & 13.9 \\
\hline \multicolumn{3}{|l|}{ Age at first pregnancy } \\
\hline$\leq 20$ years & 1155 & 89.3 \\
\hline$>20$ years & 139 & 10.7 \\
\hline \multicolumn{3}{|l|}{ Birth order } \\
\hline$\leq 3 r d$ & 671 & 51.9 \\
\hline$>3 r d$ & 623 & 48.1 \\
\hline \multicolumn{3}{|l|}{ Birth outcome of the last child } \\
\hline Live full term & 1275 & 98.5 \\
\hline Live preterm & 12 & 0.9 \\
\hline Stillbirth & 7 & 0.5 \\
\hline \multicolumn{3}{|l|}{ Gravidity } \\
\hline Primigravida & 216 & 16.7 \\
\hline Multigravida & 1078 & 83.3 \\
\hline \multicolumn{3}{|l|}{ Parity } \\
\hline Primipara & 235 & 18.2 \\
\hline Multipara & 1059 & 81.8 \\
\hline \multicolumn{3}{|l|}{ History of stillbirth } \\
\hline No stillbirth & 1199 & 92.6 \\
\hline Had stillbirth & 95 & 7.4 \\
\hline \multicolumn{3}{|l|}{ History of abortion } \\
\hline No history of abortion & 1200 & 92.7 \\
\hline Had a history of abortion & 94 & 7.3 \\
\hline \multicolumn{3}{|l|}{ History of infant death } \\
\hline No history of infant death & 1030 & 79.6 \\
\hline Had a history of infant death & 264 & 20.4 \\
\hline \multicolumn{3}{|l|}{ Pregnancy intention for last birth } \\
\hline Intended & 917 & 70.9 \\
\hline Unintended & 377 & 29.1 \\
\hline \multicolumn{3}{|l|}{ ANC use (at least one visit) } \\
\hline Yes & 693 & 53.6 \\
\hline No & 601 & 46.4 \\
\hline
\end{tabular}

4.53) than those who had not received maternal health education. Multiparous women with no previous experience of receiving skilled delivery care had lower odds of skilled delivery care utilization for subsequent births (AOR, 0.08; 95\% CI: 0.05, 0.13) than their counterparts. Multiparous women whose best friends did not use maternal care had decreased odds of skilled delivery care use (AOR, 0.43; 95\% CI: 0.29, 0.64) than multiparous women whose best friends used maternal care.
Table 3 Skilled delivery care utilization among respondents, Kersa district, eastern Ethiopia

\begin{tabular}{lcc}
\hline Variable & Frequency & Percentage \\
\hline Skilled delivery care for previous pregnancies $(n=1059)$ & \\
Yes & 213 & 20.1 \\
No & 846 & 79.9
\end{tabular}

Skilled delivery care for the recent pregnancy $(n=1294)$

$\begin{array}{lll}\text { Yes } & 398 & 30.8 \\ \text { No } & 896 & 69.2\end{array}$

Place of delivery for the recent pregnancy $(n=1294)$

Government hospital $\quad 71 \quad 5.5$

Government health centre $\quad 306 \quad 23.6$

Government health post $\quad 17 \quad 1.3$

Private hospital/clinic $\quad 3 \quad 0.2$

$\begin{array}{lll}\text { Home } & 890 & 68.8\end{array}$

$\begin{array}{lll}\text { Other (e.g. on the road) } & 7 & 0.5\end{array}$

Reason to prefer that facility for delivery $\left(n=397^{* *}\right)$

Close to where I live $\quad 194 \quad 48.9$

Helpfulness of health workers $\quad 79 \quad 19.9$

$\begin{array}{lll}\text { High-quality services } & 91 & 22.9\end{array}$

Little or no expenses $\quad 21 \quad 5.3$

$\begin{array}{lll}\text { Other reasons } & 12 & 3.02\end{array}$

Person attending the care at the health facility $(n=397)$

$\begin{array}{lll}\text { Doctor } & 47 & 11.8 \\ \text { Health officer } & 11 & 2.8 \\ \text { Nurse/midwife } & 326 & 82.2 \\ \text { Health Extension Worker } & 13 & 3.3\end{array}$

Who made final decision to deliver at the health facility $(n=397)$

Yourself 195

Your husband $\quad 86 \quad 217$

Jointly with your husband $\quad 45 \quad 11.5$

Health Extension Worker $\quad 41 \quad 10.3$

Your parents $\quad 14 \quad 3.5$

Mother-in-law $\quad 6 \quad 1.5$

Women's Development Army leader $\quad 5 \quad 1.3$

$\begin{array}{lll}\text { Other } & 5 & 1.3\end{array}$

Who accompanied to the health facility $(n=397)$

$\begin{array}{lll}\text { Partner } & 305 & 76.8\end{array}$

Women's Development Army leader $\quad 50 \quad 12.6$

Health Extension Workers $\quad 20 \quad 5.0$

$\begin{array}{lll}\text { Traditional birth attendants } & 53 & 13.4\end{array}$

No one $\quad 32 \quad 8.1$

Birth preparedness $(n=397)$

$\begin{array}{lll}\text { Yes } & 156 & 39.3 \\ \text { No } & 235 & 59.2 \\ \text { Don't remember } & 6 & 1.5\end{array}$

**The total number of respondents who delivered at a health facility. The number of women who received skilled care from either a (doctor, nurse/ midwife, or health officer) is 398 regardless of the place of delivery. The number of women who were assisted with skilled personnel within a facility is 384. [Birth preparedness: An advance preparation and planning for birth by the woman and her family] 
Table 4 Referral, prior plan for facility birth, and complications during delivery among women in Kersa district, eastern Ethiopia, 2017

\begin{tabular}{|c|c|c|}
\hline Variable & Frequency & Percentage \\
\hline \multicolumn{3}{|l|}{ Referral to a higher facility $(n=397)$} \\
\hline Yes & 46 & 11.6 \\
\hline No & 351 & 88.4 \\
\hline \multicolumn{3}{|l|}{ Prior plan for health facility delivery $(n=397)$} \\
\hline Yes & 317 & 79.8 \\
\hline No & 73 & 18.4 \\
\hline Don't know & 7 & 1.8 \\
\hline \multicolumn{3}{|l|}{ Presence of complication during delivery $(n=1294)$} \\
\hline Yes & 94 & 7.3 \\
\hline No & 1197 & 92.5 \\
\hline Don't know & 3 & 0.2 \\
\hline \multicolumn{3}{|l|}{ Type of complications during delivery* $(n=94)$} \\
\hline Severe bleeding & 28 & 29.8 \\
\hline Severe headache & 25 & 26.6 \\
\hline Convulsions & 8 & 8.5 \\
\hline High fever & 12 & 12.8 \\
\hline Loss of consciousness & 13 & 13.8 \\
\hline Labour lasting $>12 \mathrm{~h}$ & 34 & 36.2 \\
\hline Placenta not delivered 30 min after the baby & 14 & 14.9 \\
\hline Other (abdominal pain and severe vomiting) & 2 & 2.1 \\
\hline \multicolumn{3}{|l|}{ Place where complication developed $(n=94)$} \\
\hline Home & 63 & 67.1 \\
\hline Health facility & 29 & 30.9 \\
\hline On the way to a health facility & 2 & 2.1 \\
\hline \multicolumn{3}{|c|}{ Sought assistance for complication during delivery $(n=94)$} \\
\hline No & 35 & 37.2 \\
\hline Yes & 59 & 62.8 \\
\hline \multicolumn{3}{|l|}{ Future choice of delivery $(n=1294)$} \\
\hline Health facility & 764 & 59.0 \\
\hline Home & 364 & 28.1 \\
\hline No plan for pregnancy & 166 & 12.8 \\
\hline \multicolumn{3}{|l|}{ Recommend facility delivery to friends $(n=397)$} \\
\hline Yes & 307 & 77.3 \\
\hline No & 90 & 22.7 \\
\hline
\end{tabular}

*Does not sum up to total due to the possibility of multiple responses

\section{Enabling factors}

Place of residence was significantly associated with skilled delivery care attendance in both multivariate logistic regression models. Urban residence had significantly increased the odds of skilled delivery care utilization ((AOR, 4.83; 95\% CI: 2.58, 9.05) in Model 1 and (AOR, 8.23; 95\% CI: 2.26, 29.97) in Model 2).

\section{Need factors}

Multiparous women with unintended pregnancies had a decreased odds of skilled delivery care utilization (AOR, 0.54; 95\% CI: 0.35, 0.84) than multiparous women with intended pregnancies. In both multivariate models, ANC attendance during the most recent pregnancy was positively associated with skilled delivery care utilization during the most recent birth ((AOR, 2.23; 95\% CI: 1.48, 3.37) in Model 1 and (AOR, 3.13; 95\% CI: 1.51, 6.46) in Model 2) (Table 5).

\section{Discussion}

This study has attempted to explore the factors that influence the uptake of skilled delivery care among reproductive-aged women in a predominantly rural district in eastern Ethiopia; and definitively quantify use. Having an educated family member; receiving education on maternal health; previous use of skilled delivery care; and, best friend's use of maternal care were significantly associated predisposing factors. Place of residence was the only significantly associated enabling factor. The significant need factors were pregnancy intention and ANC attendance for the most recent pregnancy.

The results of the current study showed that the utilization of skilled delivery care among reproductiveaged women was $30.8 \%$. This figure reflects findings of an Ethiopian national Demographic and Health Survey report [10], where $28 \%$ of the women delivered their most recent baby with the assistance of a skilled provider; as well as a study conducted in Southern Ethiopia [18] in which $31 \%$ of women utilized skilled delivery care during their delivery. However, our result is higher than several other studies in Ethiopia [14, 15, 37, 38]. The relatively higher level of skilled delivery care utilization in our study may reflect current efforts to reduce home delivery using financial penalties for traditional birth attendants and local pregnant women who opt for home births. Moreover, the evolution of the Women's Development Army network at the village level might have contributed to better uptake of skilled delivery care through health discussions within the network during regular meetings. The varying level of service uptake underscores the requirement for local-level research to highlight the setting-specific factors that either impede or facilitate service utilization, thereby informing the development of locally suitable programs.

The findings of the present study demonstrate that the predisposing factors associated with skilled delivery care utilization were: having an educated family member: receiving education on maternal health: previous use of skilled delivery care: and, best friend's use of maternal care. Multiparous women who have an educated family member in their household have increased odds of using skilled delivery care. The influence that the educated 
Table 5 Factors associated with the utilization of skilled delivery care among women in Kersa district, eastern Ethiopia, 2017

\begin{tabular}{|c|c|c|c|c|c|}
\hline \multirow[t]{2}{*}{ Variables } & \multirow[t]{2}{*}{ Categories } & \multicolumn{2}{|c|}{$\begin{array}{l}\text { Skilled delivery care use } \\
\text { ( } n=1059) \text { Model } 1 \\
\text { (Multiparous women) }\end{array}$} & \multicolumn{2}{|c|}{$\begin{array}{l}\text { Skilled delivery care use }(n=235) \\
\text { Model } 2 \\
\text { (Primiparous women) }\end{array}$} \\
\hline & & COR $(95 \% \mathrm{Cl})$ & AOR $(95 \% \mathrm{Cl})$ & COR $(95 \% \mathrm{Cl})$ & AOR $(95 \% \mathrm{Cl})$ \\
\hline \multicolumn{6}{|l|}{ Predisposing factors } \\
\hline \multirow[t]{2}{*}{ Educational status } & Never attended & 1 & 1 & 1 & 1 \\
\hline & Attended & $3.55(2.62,4.80)$ & $1.37(0.84,2.22)$ & $4.89(2.81,8.50)$ & $1.09(0.50,2.38)$ \\
\hline \multirow[t]{2}{*}{ Partner's educational level } & Never attended & 1 & 1 & 1 & 1 \\
\hline & Attended & $2.06(1.57,2.72)$ & $0.86(0.58,1.29)$ & $4.50(2.52,8.03)$ & $1.97(0.91,4.27)$ \\
\hline \multirow{2}{*}{$\begin{array}{l}\text { Presence of another educated } \\
\text { family member }\end{array}$} & Yes & $2.05(1.55,2.70)$ & $1.89(1.26,2.85)$ & $5.77(2.95,11.29)$ & $1.36(0.51,3.61)$ \\
\hline & No & 1 & 1 & 1 & 1 \\
\hline \multirow[t]{2}{*}{ Educated about maternal health } & Yes & $1.50(1.14,1.97)$ & $1.17(0.80,1.71)$ & $2.66(1.57,4.51)$ & $2.22(1.09,4.53)$ \\
\hline & No & 1 & 1 & 1 & 1 \\
\hline \multirow[t]{2}{*}{ Mass media availability at home } & Yes & $1.98(1.50,2.62)$ & $0.99(0.64,1.55)$ & $2.30(1.36,3.89)$ & $0.88(0.41,1.90)$ \\
\hline & No & 1 & 1 & 1 & 1 \\
\hline \multirow{2}{*}{$\begin{array}{l}\text { Telephone ownership at } \\
\text { household level }\end{array}$} & Yes & $2.37(1.76,3.19)$ & $1.07(0.66,1.74)$ & $4.03(2.30,7.08)$ & $1.58(0.69,3.62)$ \\
\hline & No & 1 & 1 & 1 & 1 \\
\hline \multirow[t]{2}{*}{ Birth order } & $\leq 3 \mathrm{rd}$ & 1 & 1 & & \\
\hline & $>3 \mathrm{rd}$ & $0.59(0.45,0.78)$ & $0.76(0.49,1.18)$ & & \\
\hline \multirow{2}{*}{$\begin{array}{l}\text { Previous use of skilled } \\
\text { delivery care }\end{array}$} & Yes & 1 & 1 & & \\
\hline & No & $0.06(0.04,0.08)$ & $0.08(0.05,0.13)$ & & \\
\hline \multirow[t]{2}{*}{ Living in a model family } & Yes & 1 & 1 & & \\
\hline & No & $0.43(0.22,0.87)$ & $1.76(0.62,5.02)$ & & \\
\hline \multirow[t]{2}{*}{ Best friend's use of maternal care } & Yes & 1 & 1 & 1 & 1 \\
\hline & No & $0.22(0.16,0.29)$ & $0.43(0.29,0.64)$ & $0.25(0.14,0.43)$ & $0.77(0.38,1.56)$ \\
\hline \multicolumn{6}{|l|}{ Enabling factors } \\
\hline \multirow[t]{2}{*}{ Residence } & Rural & 1 & 1 & 1 & 1 \\
\hline & Urban & $14.42(9.09,22.88)$ & $4.83(2.58,9.05)^{* *}$ & $23.71(8.18,68.73)$ & $8.23(2.26,29.97)^{* *}$ \\
\hline \multirow[t]{5}{*}{ Wealth index } & Highest & $1.88(1.21,2.90)$ & $1.80(0.98,3.32)$ & & \\
\hline & Fourth & $1.72(1.11,2.67)$ & $1.45(0.80,2.64)$ & & \\
\hline & Middle & $1.37(0.88,2.24)$ & $1.63(0.90,2.94)$ & & \\
\hline & Second & $0.83(0.52,1.32)$ & $0.81(0.44,1.49)$ & & \\
\hline & Lowest & 1 & 1 & & \\
\hline \multirow{3}{*}{$\begin{array}{l}\text { Decision making on } \\
\text { household expenses }\end{array}$} & Respondent & 1 & 1 & 1 & 1 \\
\hline & Jointly & $1.10(0.75,1.61)$ & $0.69(0.42,1.12)$ & $2.49(1.07,5.78)$ & $1.83(0.67,4.97)$ \\
\hline & Partner & $1.95(1.20,3.18)$ & $1.65(0.84,3.23)$ & $1.83(0.70,4.79)$ & $2.90(0.87,9.71)$ \\
\hline \multirow[t]{2}{*}{ Social support from friends } & Yes & 1 & 1 & 1 & 1 \\
\hline & No & $0.34(0.18,0.62)$ & $0.58(0.27,1.25)$ & $0.30(0.14,0.64)$ & $0.71(0.29,1.76)$ \\
\hline \multicolumn{6}{|l|}{ Need factors } \\
\hline \multirow[t]{2}{*}{ History of infant death } & Have no history & 1 & 1 & & \\
\hline & Have history & $0.68(0.49,0.95)$ & $1.09(0.70,1.72)$ & & \\
\hline \multirow[t]{2}{*}{ Pregnancy intention } & Intended & 1 & 1 & & \\
\hline & Unintended & $0.50(0.37,0.69)$ & $0.54(0.35,0.84)$ & & \\
\hline \multirow{2}{*}{$\begin{array}{l}\text { ANC attendance for the } \\
\text { most recent pregnancy }\end{array}$} & Yes & $5.10(3.70,7.02)$ & $2.23(1.48,3.37)^{* *}$ & $6.96(3.86,12.53)$ & $3.13(1.51,6.46)^{* *}$ \\
\hline & No & 1 & 1 & 1 & 1 \\
\hline
\end{tabular}


family member had on the woman's acceptance of utilizing material care is paramount. It has been shown [39] that living in close proximity to people with a higher level of education can strongly influence the health service seeking behaviour of women. People with more education tend to have healthier behaviours, and good knowledge and understanding about the importance of health care utilization [40]. In relation to this, primiparous women who had received education on maternal health have increased odds of skilled delivery care utilization than primiparous women who had not received maternal health education. Educating women about maternal health increases their understanding of the importance of attending maternal health services; and the possible catastrophic consequences of pregnancy or birth complications; contributing to their acceptance and uptake of skilled delivery care. This positive impact of maternal health knowledge on the uptake of skilled delivery care has been evidenced in a previous study in Nepal [41].

Previous experience of using skilled delivery care was significantly associated with skilled delivery care utilization. The finding may indicate that women perceived the delivery care services they had received during the previous birth to be quality and appropriate. The association of previous care experience with future use of skilled delivery care might also reflect the confounding effect of accessibility and availability of services. The women who previously used skilled delivery care that subsequently attend the same service might already have better accessibility to the service, which continues to be available for the subsequent births, unlike women who do not use the service. However, in a study conducted in northwest Ethiopia [42] contrasting results were found, in that previous attendance of delivery care had a limited role in increasing the uptake of skilled delivery care for the subsequent birth. This difference may highlight the variation in terms of quality of care at different levels of primary health care facilities in Ethiopia. Moreover, in Ethiopia, concerted efforts should be made to improve the quality of obstetric care at health facilities to increase the utilization of skilled delivery care.

Our findings showed that the best friend's non-use of maternal care is significantly associated with poor uptake of skilled delivery care. The result was comparable with a study conducted in Mali [39], where women's healthseeking and utilization behaviour towards maternal care use was significantly influenced by the care-seeking practices of the surrounding people in their areas of residence. Friends are often connected through providing moral support to one another which influences the decision either to refuse or accept a temptation [43]. Women are more likely to adopt unhealthy/healthy behaviours from their best friends than strangers [44], especially in regard to gendered issues they experience in common, such as pregnancy or birthing. During their interactions with friends, fear and stigma are decreased, allowing women to freely discuss their delivery choices and therefore a adopt bad or good care-seeking behaviour. This implies that there is a possible benefit in organizing maternal health programs that target networks at the community level, as opposed to individuals. The Women's Development Army network, already established in most districts of Ethiopia, is an ideal platform and resource to facilitate such programs. Peer education programs customised specifically for women's social networks at the village level have great potential to accelerate improved attendance of skilled delivery care.

We also revealed in this study that place of residence is a significantly associated enabling factor for skilled delivery care utilization. Urban women have increased odds of utilizing skilled delivery care compared to rural women. The association of urban residence with better uptake of maternal care is consistent with the findings from other studies in Ethiopia [18, 20, 42, 45], and elsewhere in sub-Saharan Africa $[46,47]$ where the odds of skilled delivery care utilization is very low among ruraldwelling women compared to urban women. Better awareness of, and access to, maternal care may account for much of the difference between urban and rural women's uptake of skilled delivery care. Additionally, as urban women generally tend to have a higher level of economic status, they can better afford the financial burden associated with utilization of the service. Local efforts to improve maternal health should, therefore, focus on improving the accessibility and availability of delivery care services during birth, and the equitable distribution of health resources in urban and rural settings.

Moreover, ANC attendance for the index pregnancy was a statistically significant need factor that was associated with skilled delivery care utilization. Women who attended ANC for the index pregnancy have higher odds of attending skilled delivery care compared to women who did not attend ANC. The finding is in agreement with a swathe of other studies in Ethiopia [14, 20, 42, 48, 49] where the use of ANC for the woman's most recent pregnancy was strongly associated with an increased likelihood of attending skilled delivery care for the most recent birth. The women had physical interactions with the health workers and the facility during ANC that might, in turn, have helped them become more confident and familiar with the health facility allowing them to seek skilled delivery care [39]. Moreover, during the ANC check-up, the women had the opportunity to receive advice and information related to the benefits of skilled delivery care as well as the potential occurrence of obstetric problems during delivery which could increase their perceived susceptibility and motivate them to attend the care $[37,50,51]$. 
Women with unintended pregnancies have lower odds of skilled delivery care utilization compared to women with intended pregnancies. These findings are consistent with those of a previous Ethiopian study [19], which showed that skilled delivery utilization is higher among women who have intended rather than unintended pregnancies. The actual linking mechanism between pregnancy intentions and the use of skilled delivery and other maternal care is unclear; however, it could be related to women's ability to having control over both their reproductive life and household resources [52].. In addition, some women with unintended pregnancies may consider abortion as an alternative to maternal health service use. Unintended pregnancies are highly indicative of an unmet need for family planning; thus, access to appropriate family planning services should be improved.

\section{Strengths and limitations}

Limiting the reference time for retrospective questions to 3 years could minimize the introduction of recall bias. The use of relatively higher sample size has given adequate power to the study. We used a digital survey tool with iPads to collect the data, which improved the quality of the data by ensuring its completeness and consistency. Incorporation of a greater number of predictor variables into the final multivariate model ensures better controlling for confounding factors. As the interviewers were resident HDSS data collectors who regularly interact with the community, social desirability bias might not be ruled out. Due to the social desirability bias, women might have tended to provide favourable responses regarding the current or past of use of delivery care and be hesitant to share their negative care experiences. Due to the cross-sectional nature of the survey design, establishing a causality inference is also difficult. Regardless of the limitations of the study, we believe that the current survey provides a quite strong indication of the factors influencing skilled delivery care utilization in a rural setting in Ethiopia.

\section{Conclusion}

More than a quarter of the surveyed women attended skilled delivery care for their most recent pregnancy. Place of residence; the presence of another educated family member; receiving maternal health education; previous use of skilled delivery care; best friend's use of maternal care; pregnancy intention; and ANC attendance for the index pregnancy; were statistically significant predisposing, enabling and need factors associated with skilled delivery care utilization. The study pointed out the key areas of possible interventions for maternal health program planners. Designing a maternal health program that entails equitable distribution of health infrastructure between rural and urban communities is recommended. Moreover, safe motherhood intervention efforts should aim to improve the quality of delivery care at health facilities which in turn retains women for subsequent attendance. Improving access to family planning services; establishing peer to peer maternal health education programs; and increasing ANC utilization - an entry point for the attendance of the subsequent maternal care including skilled delivery care - are all strategies to be considered to increase maternal service uptake.

\section{Abbreviations}

ANC: Antenatal Care; AOR: Adjusted Odds Ratio; Cl: Confidence Interval; COR: Crude Odds Ratio; HDSS: Health and Demographic Surveillance System; SPSS: Statistical Program for Social Science

\section{Acknowledgments}

We would like to extend our thanks to the University of Newcastle, Australia for supporting the research and Haramaya University for facilitating the data collection process. We are indebted to the data collectors and the

supervisor, local collaborators and the study participants.

\section{Authors' contributions}

GT designed the study. CC, RS, and DL critically revised the design and planning of the study. CC, RS, and DL substantially contributed to the inception, design, acquisition, analysis, and interpretation of the data. GT drafted the manuscript. CC, RS, and DL critically revised the manuscript for important intellectual contents. All authors read, provided feedback and approved the final manuscript.

\section{Funding}

This research was supported by the University of Newcastle, Australia as part of the research training program for research higher degree students. Haramaya University supported the facilitation of the data collection process by providing vehicles for fieldwork. The sources of the research funding had no role in the design of the study, data collection, data analysis, and interpretation of the study.

\section{Availability of data and materials}

The data used for this study can be made available upon reasonable request to the authors.

\section{Ethics approval and consent to participate}

The study was conducted after securing ethical approval from the Human Research Ethics Committee (HREC) of the University of Newcastle, Australia, and the Institution Health Research Ethics Committee (IHREC) of College of Health and Medical Sciences, Haramaya University, Ethiopia. Informed verbal consent was obtained from each respondent before commencing the interviews. The confidentiality of the respondents was kept by avoiding personal identification details.

Consent for publication

Not applicable.

\section{Competing interests}

The authors declare that they have no competing interests.

\section{Author details}

${ }^{1}$ School of Public Health, College of Health and Medical Sciences, Haramaya University, P.O Box: 235, Harar, Ethiopia. ${ }^{2}$ Research Centre for Generational Health and Ageing, Faculty of Health and Medicine University of Newcastle, Newcastle upon Tyne, NSW, Australia. ${ }^{3}$ Mothers and Babies Research Centre, Faculty of Health and Medicine, University of Newcastle, Newcastle, NSW, Australia. 
Received: 24 July 2018 Accepted: 28 October 2019

Published online: 15 November 2019

\section{References}

1. WHO. Trends in Maternal Mortality: 1990 to 2015 Estimates by WHO UNICEF, UNFPA, World Bank Group and the United Nations Population Division. 2015.

2. Bayu H, Adefris M, Amano A, Abuhay M. Pregnant women's preference and factors associated with institutional delivery service utilization in Debra Markos Town, North West Ethiopia: a community based follow up study. BMC Pregnancy Childbirth. 2015;15(15).

3. Bryce J, Black R, Victora C. Millennium development goals 4 and 5: progress and challenges. BMC Med. 2013;11(225):1-4.

4. Graham W, Bell J, Bullough C. Can skilled attendance at delivery reduce maternal mortality in developing countries? vol. 17: Studies in HSO \& P; 2001:97-129.

5. Berhan Y, Berhan A. Commentary: Actions in the pipline and the way forward to reduce maternal and perinatal mortality in Ethiopia. Ethiop $J$ Health Sci. 2014;(Special issue):149-64.

6. Campbell O, Graham W. Strategies for reducing maternal mortality: getting on with what works. Lancet. 2006;368:1284-99.

7. Ronsmans C, Graham W. Maternal mortality: who, when, where, and why. Lancet. 2006;368(9542):1189-200.

8. UoA. "Skilled birth attendance in the developing world in comparison with the developed world. Consequences to the mother and child mortality. Where do we stand nowadays?" 2013. Available from: http://crisis.med.uoa. gr/elibrary/12.pdf.

9. UN. The Millennium Development Goals Report. 2011.

10. CSA. Ethiopian Demographic and Health Survey 2016.

11. UNFPA. Key actions for the further implementation of the Programme of Action of the International Conference on Population and Development +5: United Nations Population Fund. New York: Twentyfirst special session; 1999.

12. Crowe S, Utley M, Costello A, Pagel C. How many births in sub-Saharan Africa and South Asia will not be attended by a skilled birth attendant between 2011 and 2015? BMC Pregnancy Childbirth. 2012;12(4).

13. Pearson L, Gandhi M, Admasu K, Keyes E. User fees and maternity services in Ethiopia. Int J Gynecol Obstet. 2011;115:311-5.

14. Amano A, Gebeyehu A, Birhanu Z. Institutional delivery service utilization in Munisa Woreda, south East Ethiopia: a community based cross-sectional study. BMC Pregnancy Childbirth. 2012;12(105):1-6.

15. Nigussie M, Hailemariam D, Mitike G. Assessment of safe delivery service utilization among women of childbearing age in north Gondar Zone, north west Ethiopia. Ethiop J Health Dev. 2004;18(3):145-52.

16. Worku A, Yalew A, Afework M. Factors affecting utilization of skilled maternal care in Northwest Ethiopia: a multilevel analysis. BMC Int Health Hum Rights. 2013;13(20).

17. Workineh $Y$, Hailu D. Factors affecting utilization of postnatal care service in Jabitena district, Amhara region. Ethiopia Sci J Public Health. 2014;2(3):169-76

18. Habte F, Demissie M. Magnitude and factors associated with institutional delivery service utilization among childbearing mothers in Cheha district, Gurage zone, SNNPR, Ethiopia: a community based cross sectional study. BMC Pregnancy Childb. 2015;15(299).

19. Dutamo Z, Assefa N, Egata G. Maternal health care use among married women in Hossaina, Ethiopia. BMC Health Serv Res. 2015;15(365).

20. Melaku Y, Weldearegawi B, Tesfay F, Abera S, Abraham L, Aregay A, et al. Poor linkages in maternal health care services? evidence on antenatal care and institutional delivery from a community-based longitudinal study in Tigray region, Ethiopia. BMC Pregnancy Childbirth. 2014;14(418)

21. CSA. The Ethiopian Mini Health and Demographic Survey. Addis Ababa, Ethiopia, Calverton, Maryland, USA: Central Statistical Agency of Ethiopia, 2014.

22. USAID/MCHIP. Cultural Barriers to Seeking Maternal Health Care in Ethiopia: A Review of the Literature. 2012

23. Regassa N. Antenatal and postnatal care service utilization in southern Ethiopia: a population-based study. Afr Health Sci. 2011;11(3):390-97.

24. Islam N, Islam MT, Yoshimura Y. Practices and determinants of delivery by skilled birth attendants in Bangladesh. Reprod Health. 2014;11:86.

25. Geneti K. Statistical analysis of determinants of maternal institutional delivery service utilization in Ethiopia. Am J Theoretical App Stat. 2015 4(3):71-7.
26. Warren C. Care seeking for maternal health: challenges remain for poor women. Ethiop J Health Dev. 2010:24(Special 1):100-4.

27. Andersen R. Revisiting the behavioural model and access to medical care: does it matter? J Health Soc Behav. 1995:36(March):1-10.

28. Anderson R, Newman JF. Societal and individual determinants of medical care utilization in the United States remove. Milbank Mem Fund Q Health Soc. 1973;51(1):95-124.

29. UNFPA. Summary and Statistical Report of 2007. Addis Ababa: Population and Housing Census; 2008.

30. CSA. Population Projection of Ethiopia for All Regions At Wereda Level from 2014-2017. 2014.

31. Kersa-DHO. Health service coverage. Kersa District Health Office, Eastern Hararge, Ethiopia. 2011.

32. Sarah M, Spencer M. On est ensemble: social capital and maternal health care use in rural Cameroon. Glob Health. 2015:11(33).

33. Assfaw $Y$. Determinants of antenatal care, institutional delivery and skilled birth attendant utilization in Samre Saharti District, Tigray, Ethiopia [master thesis ]: Umea; 2010

34. Ayele D, Belayihun B, Teji K, Ayana D. Factors affecting utilization of maternal health Care Services in Kombolcha District, eastern Hararghe zone, Oromia regional state, Eastern Ethiopia. Int Sch Res Notices. 2014;2014:7.

35. CSA. Ethiopia Demographic and Health Survey 2011 Addis Ababa, Ethiopia and Calverton. Maryland: Central Statistical Agency and ICF International; 2011.

36. JHPIEGO. Tools and indicators for maternal and newborn health 2004

37. Tsegay Y, Gebrehiwot T, Goicolea I, Edin K, Lemma H, Sebastian M. Determinants of antenatal and delivery care utilization in Tigray region, Ethiopia: a cross-sectional study. Int J Equity Health. 2013;12(30).

38. Medhanyie A, Spigt M, Kifle Y, Schaay N, Sanders D, Blanco R, et al. The role of health extension workers in improving utilization of maternal health services in rural areas in Ethiopia: a cross sectional study. BMC Health Serv Res. 2012;12(352).

39. Anastasia J. Barriers to the utilization of maternal health care in rural Mali. Soc Sci Med. 2007;2007(65):1666-82.

40. Zimmerman E, Woolf SH. Understanding the relationship between education and health; 2014.

41. Karkee $\mathrm{R}$, Baral OB, Khanal V, Lee AH. The role of obstetric knowledge in utilization of delivery service in Nepal. Health Educ Res. 2014;29(6):1041-8.

42. Kebede B, Gebeyehu A, Andargie G. Use of previous maternal health services has a limited role in reattendance for skilled institutional delivery: cross-sectional survey in Northwest Ethiopia. Int J Women's Health. 2013; 2013(5):79-85

43. Lowe ML, Haws KL. (Im) moral support: the social outcomes of parallel selfcontrol decisions. J Consum Res. 2014:41(2):489-505.

44. Story WT. Social capital and the utilization of maternal and child health services in India: a multilevel analysis. Health Place. 2015;28:73-84.

45. Fikre A, Demissie M. Prevalence of institutional delivery and associated factors in Dodota Woreda (district), Oromia regional state, Ethiopia. Reprod Health. 2012;9(33):1-6.

46. Exavery A, Kanté A, Njozi M, Tani K, Doctor $H$, Hingora A, et al. Access to institutional delivery care and reasons for home delivery in three districts of Tanzania. Int J Equity Health. 2014;13(48):1-11.

47. Fapohunda B, Orobaton N. When Women Deliver with No One Present in Nigeria: Who, What, Where and So What? PLoS One. 2015;8(7).

48. Wado $Y$, Fantahun M, Hindin M. Unintended pregnancies and the use of maternal health services in southwestern Ethiopia. BMC Int Health Hum Rights. 2013;13(36):1-8.

49. Birmeta $K$, Dibaba $Y$, Woldeyohannes $D$. Determinants of maternal health care utilization in Holeta town, central Ethiopia. BMC Health Serv Res. 2013;13(256).

50. Turyasiima M, Tugume R, Openy A, Ahairwomugisha E, Opio R, Ntunguka M, et al. Determinants of first antenatal care visit by pregnant women at community based education, research and service sites in northern Uganda. East Afr Med J. 2014:91(9):317-22.

51. Bogale D, Markos D. Knowledge of obstetric danger signs among child bearing age women in Goba district, Ethiopia: a cross-sectional study. BMC Pregnancy Childbirth. 2014;15(77)

52. JO P, Penn-Kekana L, Blaauw D, Balabanova D, Danishevski K, Rahman SA, et al. Health systems factors influencing maternal health services: a fourcountry comparison. Health Policy. 2005;73(2):127-38.

\section{Publisher's Note}

Springer Nature remains neutral with regard to jurisdictional claims in published maps and institutional affiliations. 